\title{
Explanations of a Violent Relationship: The Male Perpetrator's Perspective
}

Jason B. Whiting PhD

Brigham Young University, jason.whiting@byu.edu

Timothy G. Parker

Austin W. Houghtaling

Follow this and additional works at: https://scholarsarchive.byu.edu/facpub

Part of the Domestic and Intimate Partner Violence Commons

\section{Original Publication Citation}

Whiting, J. B., Parker, T., \& Houghtaling, A. (2014). Explanations of a Violent Relationship: The Male Perpetrator's Perspective. Journal of Family Violence, DOI: 10.1007/s10896-014-9582-9

\section{BYU ScholarsArchive Citation}

Whiting, Jason B. PhD; Parker, Timothy G.; and Houghtaling, Austin W., "Explanations of a Violent Relationship: The Male Perpetrator's Perspective" (2014). Faculty Publications. 2170.

https://scholarsarchive.byu.edu/facpub/2170 


\title{
Explanations of a Violent Relationship: The Male Perpetrator's Perspective
}

\author{
Jason B. Whiting • Timothy G. Parker • \\ Austin W. Houghtaling
}

(C) Springer Science+Business Media New York 2014

\begin{abstract}
The purpose of this study was to understand the way male perpetrators' perceive and explain intimate partner violence (IPV) in their relationship. Specifically, men were invited to reflect upon their role in their relationship when violence exists, their contributions to the violence, and how they felt about it. Using coding procedures from grounded theory methodology, researchers analyzed data from 13 men who had been in violent relationships. Seven key themes were identified from 104 significant statements. These themes included justification, relapse, control, anger, emotional threshold, triggers, and remorse. Clinical implications as well as suggestions for future research are presented.
\end{abstract}

Keywords Intimate partner violence · Gender · Perpetrator · Rationalization

Intimate partner violence (IPV) is a serious problem nationally and internationally. It is a human rights issue, a public health concern, and a challenge for professionals. Approximately one in four women in the United States will experience at least one incident of physical violence from their present or former male intimate partner in their lifetime. Surveys also suggest that just over half of all incidents of partner violence are reported to the police (National Coalition Against Domestic Violence 2007) and that violence is often underreported in relationships (O'Leary and Williams 2006). World Health Organization researchers found that severe and continuous partner violence exists at rates in most geographic areas between 29 and $62 \%$ (Garcia-Monroe et al. 2006).

J. B. Whiting $(\bowtie) \cdot$ T. G. Parker

Marriage and Family Therapy Program, Texas Tech University,

Box 41210, Lubbock, TX 79409-1210, USA

e-mail: jason.whiting@ttu.edu

\section{A. W. Houghtaling}

Breakthrough at Caron, Wernersville, PA, USA
Intimate partner violence occurs in couples from all socioeconomic levels, ethnic backgrounds, and sexual orientations (e.g., Johnson 2008).

IPV usually consists of a pattern of abusive behaviors that can include physical, sexual, and psychological aggression. It often involves control and intentional use of behaviors to maintain control. There are, however, different patterns and types of intimate partner violence. Johnson (2008) has suggested a typology of IPV based on patterns of escalation and control. Situational couple violence occurs when a disagreement escalates into physical violence such as shoving, throwing, hitting, or worse. This also can involve violence as an expression of anger or frustration, but is not usually accompanied by control. This type of violence is as likely to be perpetrated by women as men, although women are more likely to sustain injury (Johnson 2008). Intimate terrorism is the type of violence usually described as "battering" and has high amounts of coercive controlling behaviors (e.g., of money, friends). This type of violence is nearly always from a male partner to a female victim, and is more serious in terms of risk of injury or death. Intimate terrorism is also more likely to be reported to police or other authorities (Hines and MalleyMorrison 2005).

There is no single reason why IPV occurs. Men's violence against women is influenced by many societal, psychological, biological and familial risk factors (O'Neil and Harway 1997). These include men's gender role socialization, alcohol and/or substance abuse, isolation, economic disadvantage, witnessing or experiencing violence in family-of-origin, child maltreatment, stress, gender inequality, and psychopathology (Coker et al. 2000; DeMaris et al. 2003; Holtzworth-Munroe and Stuart 1994).

Although violence against men does occur, its severity and consequences are usually less serious compared with male violence against women (Jaden and Thoennes 2000). For example, women who are violent are less likely to terrorize 
or traumatize their partners than are violent men (Johnson 2006). Also, men are much more likely to inflict serious injury to women than the reverse (Goldner 1999). Additionally, some female violence is termed "violent resistance" because it occurs only in response to male abuse or domination (Johnson and Ferraro 2000). This happens when controlling men deliberately provoke women into being violent; this becomes their excuse for retaliating (Whiting et al. 2012).

Men are more likely to be controlling in addition to violent. Feminist scholars suggest this may be because the structural elements of patriarchy in society make it acceptable for men to be domineering and aggressive (Dobash and Dobash 1981). As one example, in the U.S., sons are less controlled than are daughters, which may suggest the acceptability of expecting female submissiveness (Grasmick et al. 1996). Additionally, critical studies of men and masculine socialization have suggested that for many men, the shame that comes from being victimized or bullied contributes to cognitive distortion regarding the need to dominate or control (Jennings and Murphy 2000). This may be one of the reasons that men feel vulnerable are more likely to react by seeking to control or dominate (Lisak 1995). Given these issues, and the fact that men continue to be the more dangerous aggressors in IPV, it is important to better understand male perpetration and male perceptual processes in violent relationships (Holtzworth-Munroe and Meehan 2005).

\section{Men's Experiences in Violent Relationships}

Much of the research on IPV is directed toward the victims of violence and some have argued that more scholarship on perpetrators is warranted (Scott Tilley and Brackley 2005). Understanding perpetrator's experiences could help clinicians know which areas to focus on while intervening. Additionally, for those running batterer intervention programs, it is important to understand the vulnerabilities and points of connection for perpetrators (e.g. Jenkins 2009). This is important since many men relapse after treatment.

Shepard et al. (2002) looked at recidivism rates at 6 months, 12 months and 18 months for men who had been mandated for batterer intervention groups. They found that those who completed treatment were less likely to repeat their violence. However, they also found that although rates of relapse were dropping, from $51 \%$ in 1994 to $33 \%$ in 1998, at least one in three men still relapsed after treatment. This is consistent with meta-analyses of violence treatment which has found that although treatment does seem to help in many cases, the effect sizes of treatment impact are small (Babcock et al. 2004).

Also, it appears that the differing models (e.g., the "Duluth" model vs. CBT) are similar to each other in regard to efficacy, although the cell sizes for these various approaches were small in this particular meta-analysis. However, Babcock and Steiner (1999) found there was a significant reduction in rates of recidivism in men who attended a group compared to those who were incarcerated only. Regardless, the success of preventing relapse through treatment is still low. Babcock et al. (2004) cautiously suggest that treatment makes relapse $5 \%$ less likely. This may be in part because we do not yet adequately understand the nuances and variations among violent men (Felson et al. 2005; Holtzworth-Munroe et al. 2000; Johnson 2008).

One of the distinguishing features of violent men is their use of cognitive distortions (Eckhardt and Dye 2000). Cognitive distortions can be defined as "inaccurate ways of attending to or conferring meaning on experience" (Barriga et al. 2000, p. 37). Studies have addressed the concept of cognitive distortion in many ways including the development of a classification of characteristics descriptive of perpetrators (Eckhardt and Dye 2000; Holtzworth-Munroe and Stuart 1994; Porcerelli et al. 2004; Ragg 1999). Denial, blame, justification and minimization are types of distortions that are used by abusive men to excuse or downplay their actions (Holtzworth-Munroe and Hutchinson 1993). Heckert and Gondolf (2000) found gender differences in distortions when it came to self-reporting violence. They compared 145 reports of domestic violence with actual police reports of the same incidents. They observed that the batterer's were more likely than their victims to minimize assault severity or deny the abusive behavior entirely in their reports of the events. Further evidence of minimization is that accounts of violence between partners often vary widely, and men often underreport their severe aggression (Heyman and Schlee 1997).

In general, men who are violent tend to have different types of thinking patterns than do men who are not violent. Eckhardt et al. (1998) investigated the thought patterns of men who had used some sort of physical aggression against an intimate partner in the last year compared with nonviolent men. They exposed 88 men to anger-arousing audiotapes. The men then gave verbal responses to each of the scenarios presented in the audiotapes and coders looked for themes of hostile attributional biases, anger control statements, cognitive biases, and irrational beliefs. Men who admitted to being violent exhibited more hostility, irrational beliefs, and cognitive biases, and fewer anger control statements than nonviolent men. Eckhardt and Kassinove (1998) similarly found that men who have been violent respond to a series of stories of relational interactions with more automatic thoughts that are characterized by distortions, exaggerations, and overgeneralizations.

Another distinguishing feature of violent men is their perception of control. In one study, hypothetical behaviors towards a romantic partner were presented to 119 college students. Participants were asked to respond as to the controlling nature of these behaviors. Men and women who had never been in a violent relationship perceived the hypothetical behaviors as more controlling (i.e. restrictive, coercive, or 
domineering) than those involved in violent relationships as either a perpetrator or a victim; and in those instances men perceived the behaviors as still less controlling than did females who had been in a violent relationship (Ehrensaft and Vivian 1999). Another difference is a low threshold for anger. Moffitt et al. (2000) found that men who are characterized by negative emotionality, or a low threshold for anger, were more likely to be abusive towards their spouse than men who possess positive emotionality.

\section{Purpose of the Study}

While research has been done in an effort to understand violent men, little has been done that specifically asks them to explain their own violence and relationship dynamics. It would be helpful to understand how men make sense out of these behaviors and attitudes within a partnership. Many existing studies on perpetrators have been quantitative in nature. Qualitative research can help to provide an insider's perspective on the various issues that characterize men who are violent. This study sought to understand perpetrators' perspectives by asking the following research questions: 1) How do men who have been violent describe their relationship in terms of abuse?; 2) What do men believe contributes to the violence?; and 3) How do they feel about the violence in their relationship? Using qualitative data, these questions were answered through an analysis of participants' views about the abuse, themselves, and their partner.

\section{Method}

\section{Participants}

Our sample included 13 males who were involved either in a batterer intervention program or in therapeutic treatment for violence. The sample contained 11 Caucasian men and two African American men. The men ranged in age from 21 to 58 with a median age of 32 . The average age of respondents was 37 . The length of time spent in abusive relationships ranged from 1 to 36.5 years with a median time of 3 years. The average amount of time spent in an abusive relationship was 7.5 years. Four of the males reported being married while three reported being single. Two of the respondents were separated while two others were divorced. Two men reported having girlfriends.

These interviews were conducted at a large Midwestern university under the auspices of the Institutional Review Board, which ensured that participants' confidentiality and rights were protected. These participants were recruited through their respective treatment facilities. They were offered either $\$ 20$ or a free therapy session, whichever was worth more to them. They met selection criteria if they had been violent in their intimate relationships and were addressing this in therapy or a mandated treatment group. Because the goal of the research was to understand the general ways in which violent men described their relationship, this sample provided a small group of men with a range of experiences to study. These participants were part of a larger data set that included men and women who were describing their interactions within relationships of varying degrees of conflict and violence (Whiting et al. 2012). This data included a semi-structured interview that asked questions about relationship aggression, attributions, and explanations for the patterns and behaviors that both partners exhibited.

\section{Procedures}

Since this study involved analysis of secondary data, we attempted to both understand the original context and purpose of the data gathering, as well as try to approach the data with an open mind (Seale 2004). This involved examining our motives and assumptions about the topic, and reviewing the original interview guide and recruitment procedures. We also took into account what the original researchers were examining before we embarked on our investigation to make sure that this data was suitable for analyzing perpetrators' experiences of IPV. Although we could not do constant comparison in the data gathering, it is acceptable to review secondary qualitative data and generate new categories of meaning for new research questions on domestic violence (e.g., Few and Rosen 2005).

We individually analyzed each transcript through coding methods from grounded theory methodology (GTM) (Corbin and Straus 2008). We chose GTM because it is used to analyze data on a micro level and generate a rich description of process and experience (LaRossa 2005). Although GTM are often used to create a model of the concepts generated, they can also be used as a way to present descriptive and organized themes (Corbin and Strauss 2008). For this analysis it was important to bracket, or set aside, previous understandings of this topic, and approach the data with curiosity without forcing constructs onto it. The coding methods we used were open and axial coding. Prior to open coding we read through each of the transcripts and pulled out what we viewed were the significant statements, or "meaning units" (Creswell 2007). After this, we applied open coding techniques to these units by labeling them with descriptors that captured the ideas they contained. Following open-coding we began axial coding, which "be$\operatorname{gin}[\mathrm{s}]$ the process of reassembling data that were fractured during open coding" (Strauss and Corbin 1998, p. 124). We were able to place the ideas from the statements generated in open-coding into identifiable categories that tied together. Through doing this we were able to discuss and decide which themes went together and which themes did not. The themes that were associated we collapsed into larger categories. 
Following the individual coding we reviewed our results as a team and identified categories that were present in all of our processes. We discussed which themes emerged as important and then took a step back to determine if they were important to us for personal reasons or because that was what the data were suggesting. After reexamining these themes we identified those themes that were most relevant for the research questions, and we discarded some and collapsed others. We identified dominant themes and placed these into clusters. These provided a better understanding of how the various themes contributed to the phenomena surrounding men's experiences with their role in a violent relationship.

\section{Results}

From 13 verbatim transcripts, 104 significant statements were extracted (See Table 1). Seven categories emerged from clustering the formulated meanings, and these roughly corresponded to the research questions. The categories justification and relapse related to question one about descriptions of their relationship. Categories related to contributions to violence included control, anger, emotional threshold, and triggers. Only one category was primarily tied to the third research question, which was remorse. Three of these categories - justification, control, and remorse - were the most thoroughly developed, with each having several subthemes. As with any qualitative findings, the organizing of the data into categories is for clarity, but there were times when certain themes related to multiple research questions (e.g., justification was found to be both a description of the relationship, as well as connected to feelings about the violence). Table 2 illustrates two examples of categories, showing the subthemes. This table is an example of how the fractured data was labeled and organized into smaller chunks (subthemes) that eventually became the broader categories. We will present examples of all of the categories (although not all of the subthemes) with representative quotes from the participants.

\section{Category 1: Justification}

Justification or rationalization of behavior was illustrated by men making comments that minimized their own abusive behavior or saying things indicating they were returning "tit for tat." Many different forms of justifying or rationalizing violent behavior existed among participants. Some of these types of justification included what we termed reciprocity (meaning, returning violent behavior with violent behavior), shifting responsibility, and minimizing issues. One man recognized his reciprocal justification in this instance:

She got aggravated with me and threw a dish, a plate, at me. I was walking out the door to my garage, and the plate hit the door and shattered the plate, so I turned around and looked at her, and said "f-you", you missed, and shut the door and went out to my garage. And the next thing I know, she comes out there and I wind up throwing stuff.

Shifting responsibility manifested itself in comments like, "you made me do this," or "She'd try and ... act like I was in the wrong, but it was her." Minimization was evident in comments like, "that didn't hurt...I can't believe you're crying over that," or "I was just playing," or "you're making a mountain out of an ant hill, it wasn't that bad."

\section{Category 2: Relapse}

These participants recalled patterns of fluctuation - an "ebb and flow" of violence and nonviolence. There was great variation in their descriptions of the frequency of violence in relationships ranging from every day to once every 6 or 7 months. One man observed, "The longer we were together the more [the violence] happened." Another man commented on his feelings of frustrations with his own fluctuating behavior: 'I'm trying, I'm trying to change period, you know, and I try, and try, and try ... I do good for so long, and then boom, I

Table 1 Selected examples of significant statements of men who engage in domestic violence and related formulated meanings

\begin{tabular}{lc}
\hline Significant statement & Formulated meaning \\
\hline $\begin{array}{l}\text { I have always been deeply upset by the abusive behaviors...I think it } \\
\text { probably troubled me more than it troubled my partner... }\end{array}$ & $\begin{array}{c}\text { Remorse of conscience is a very real component for some } \\
\text { men engaged in or experiencing domestic violence. } \\
\text { I just wouldn't let it go, I would just keep on telling her that...if she }\end{array}$ \\
$\begin{array}{l}\text { wouldn't have done it, I wouldn't have done it. } \\
\text { really, in my opinion, as a woman, doing the same likewise, a } \\
\text { their behavior on their partner. } \\
\text { woman beating up on a man don't make her much of a woman either. } \\
\text { I would get mad at her over little, minor, small stuff, stuff that I shouldn't } \\
\text { normally get mad about, I'd get upset, it would tick me off, we would } \\
\text { start arguing, and then pushing and shoving and then me hitting her. }\end{array}$ & $\begin{array}{c}\text { The idea of triggers is important to consider. Some triggers } \\
\text { may be more obvious than others, and most likely are }\end{array}$ \\
\hline
\end{tabular}


Table 2 Two theme clusters with their associated meanings

\begin{tabular}{l}
\hline Justification/rationalization \\
\hline Reciprocity \\
Blame \\
Minimization \\
Shifting responsibility \\
Remorse or regret \\
Shame \\
Value system \\
Amelioration attempts \\
Coping \\
Apology \\
Taking responsibility \\
Professional counseling \\
Value system
\end{tabular}

relapse." Other participants expressed determination to work towards nonviolence in words such as these:

I don't think that I will ever put my hands on her again. Arguing might happen -anybody's going to argue if they have difference or whatever-but my thinking is if I do come across an argument ... it's me learning more how to deal with the situation. Can I deal with the pressure and ... accept feedback that I don't want to hear?

\section{Category 3: Control}

This category involved themes such as lies and deceit, intimidation, and various forms of abuse (i.e. physical, emotional, and/or verbal) that were used to control a partner. Some admitted using behaviors such as "the silent treatment" or other manipulative actions. Other forms of control were described including intimidation, lies/deceit, as well as violence. One man tried to control his wife's reaction to his violence:

"When I see the tears ... I try to soften her up, saying, 'hey girl ... it wasn't meant how you thought ...' But I'm lying... I knew I was lying, she knew I was lying too."

Another said, "I had some insight to see that my behavior was deliberate and premeditated control." Another admitted, "I was subconsciously believing that it was okay to use violence to control her." Many respondents commented on how their attempts to establish or maintain control were detrimental to the relationship.

Many forms of verbal, emotional, and physical abuse as a means to control were reported by participants including behaviors such as name calling, pulling hair, slapping, hitting, giving their partner "the silent treatment," etc. An example was reported by one participant when he said, "when she'd refuse to stop talking at night, I'd roll over in the bed and choke her". There were justifications some men had for their control. One said: "She cheated on me three times, and... I would think, maybe if I was more...controlling it would have never happened."

\section{Category 4: Anger}

Most of the men mentioned anger in their lives and in their relationships with their partners. The men talked about how anger towards their partners could lead to a violent incident. One man described this connection:

"I felt the rage starting up, the adrenaline, and I just didn't care. I just kept going and going. It was at that moment in time, that I was looking at her, I honestly just wanted to hurt her physically."

In many instances the men were able to identify negative consequences of their anger and discussed trying to overcome anger issues. One man described this: "I knew that somewhere down the line it was going to cost [the relationship] ... I was being an ass to her." Many claimed an inability to control their anger. One said, "I could walk through the door, and she'd come and give me a kiss and hug me, and the kids would come up- just something, the least little thing, and I'd go off."

\section{Category 5: Emotional Threshold}

Many participants described a threshold that would get overcome when they "snapped" and became violent. One man described this as "flooding." He said, "You are flooded with feeling. It's very difficult to be as controlled as I would like to be of my own . . . behaviors at that time." Another man reported, "There were times when I . . . couldn't take it anymore." Interestingly, a common reaction to hitting an emotional threshold was to give an ultimatum. Often this ultimatum consisted of threatening the partner with leaving or other drastic behavior. One respondent who was overwhelmed with his wife's alcohol dependence said,

"I told her, I said you've got 3 days, I'll go stay with my parents for 3 days . . . and then when I come back, if you're still thrashed, you'll be trashed. I'll throw your stuff out in the yard."

\section{Category 6: Triggers}

Participants described a wide range or experiences, thoughts, emotions, interactions, and other things serving as triggers for them to instigate violent behaviors. Some participants reported getting mad "over little, minor, small stuff" that did not warrant the ensuing violent behavior. Others mentioned specific stressors such as being the single financial supporter of the family, or 
having a wife who was also violent. One participant noted that his stressor was his partner's alcohol problem. When asked how an abusive incident would play out one responded: "she would get to drinking and I wouldn't like it so I would leave and try to cool down, wait until she goes to sleep, and I would go back home." He recognized that even though her drinking was a trigger for him, if he avoided it he might be able to avoid the abusive incident. Many triggers did not pertain directly to their relationship, but were perceived to be related to things like childhood events or external stressors (e.g., work, finances, etc.).

\section{Category 7: Remorse}

Most respondents mentioned some form of remorse or regret about their violent behaviors. One man said, "I have always been deeply upset by the abusive behaviors." Some of these feelings of regret were seen in comments where shame was apparent for certain behaviors (i.e. being arrested in front of one's children). Others discussed efforts made to ameliorate the situation after it had turned violent. Several forms of apologies were mentioned as well as various forms of taking responsibility. Comments such as, 'I always react before I think, but I'll try to learn how to think before I react that way I won't find myself in a situation," and, "I was in the wrong forever putting my hands on her" are examples of how these men spoke in ways that showed awareness for their actions. Some of the participants reported seeking out professional help or counseling in order to improve or salvage their relationships. Personal improvement was noted for one man in particular who said, "I'm substantially less volcanic than I was 20 years ago. [Partner] is probably stronger than she was 20 years ago. The context of how we argue has changed tremendously with therapy together."

Several of the men described needing to rebuild trust after it had been destroyed from their violent behavior (e.g., "Trust is my biggest problem now, it's hard"). Rebuilding trust was described as connected to remorse of action. Also, men reported remorse with regard to the effect their behavior had on their children. Children, in some instances, helped keep participants' behavior from escalating, as evidenced in the following:

Her kids . . . meant the world to me, and when we would argue that would be one of the very few things that popped in my head were the kids, they are going to wind up seeing this, they're going to wind up hearing this, I would rather them see their mom drink than see their mom get pushed to the floor.

\section{Discussion}

Our findings on perpetrator's perspectives overlap in various ways with the research reviewed at the beginning of the paper. For example, anger is a common component in the personality traits of perpetrators of IPV (e.g., Holtzworth-Munroe et al. 2000). However, our findings suggest that men can reflect on their anger and its role when they are discussing it after an incident. Similarly, others have found that violent men have a desire to control their partner (Felson and Messner 2000), although in our study this was identified by the perpetrators rather than by external raters.

Although some scholars have explored the role of triggers in perpetration (e.g., Hattery 2008) direct research on this phenomenon is limited. Some of the men in our study reported that they would have avoided the violent incident if they had adequate coping skills to handle their triggers. However, even while using these explanations of triggers as excuses, these men still described their choices and regrets in this process. This is relevant because it shows that when challenged or given a chance to reflect on the violence, many men do not prefer to be violent, even though they sometimes rationalize it (e.g., Jenkins 2009). It is important to find ways to hold men accountable for their behavior, while at the same time better understand the role of interaction and contextual triggers in IPV (e. g. Wilkinson and Hamerschlag 2004).

Cognitive distortions play a key role in the rationalization of violence, and these men used variations of distortions that have been found by others (Eiskovits and Enosh 1997; Barnett et al. 1997). Importantly, most of the men in our study recognized and admitted to using distortion when asked about it. This was something that may not have been predicted by the literature, since other studies tend to focus solely on how violent men downplay or blame their violence on others instead of taking responsibility for it (e.g., Eckhardt and Kassinove 1998). The consistency of comments about distortion and rationalization leads us to further appreciate how complex and ingrained this is in some men's thinking and behavioral patterns.

Further illustrating the complexity of these men's perceptions was the discovery that most interviews contained mixtures of both blaming and responsible explanations. As we disentangled these into themes, it was clear that sometimes men switched quickly from excusing their actions to expressing remorse for them. Although almost all of the respondents in this study voiced some concern about their behavior, this is not a common finding in studies of perpetrators. This may be because of the reluctance researchers or professionals have of appearing to soften or excuse male violence. Although we believe that violence is inexcusable, we think that it is important to understand its complexity in order to not dismiss or over simplify it (Johnson 2006). Professionals who can appreciate this are in a better position to intervene with violence. We do understand, however, it is difficult to separate genuine from fake remorse designed to manipulate a partner or a professional. In our analysis, we identified constructs including shame, the participant's value system, as well as amelioration attempts. Although we are hopeful that these were for the most part sincere, we also 
know from victim's stories that some of this could have been manipulative (Felson et al. 2005).

Implications for Therapists and Professionals

This study has implications for therapists working with male perpetrators of IPV. As mentioned, violence is a persistent problem for many men and relapse rates for men who undergo treatment are common. Further experimenting with elements of treatment is an important way to improve its efficacy. For example, this project suggests that it is important for therapists to access men's remorse or regret about their behaviors (e.g., Jenkins 2009). Increasing men's empathy in this way may lead to a decrease in aggression (Richardson et al. 1994). Talking about remorse or regret may also open the door to discussing the perpetrator's value system and how the violence likely contradicts his values or self-image. Identifying guilt connected with betraying one's value system can help men decrease their need to rationalize or distort their behavior.

Also, therapists need to identify the varying triggers for perpetrators. Some participants suggested that knowing what their triggers were and how to handle them would have prevented them from becoming violent with their partner. Interventions designed to improve client's ability to self soothe, or to acknowledge angry feelings without acting on them could be an important part prevention and change. IPV programs that specifically incorporate elements of mindfulness or negotiated time outs have shown to be efficacious in this regard (Stith et al. 2005).

This study also confirms that it is crucial to assess for and highlight issues of control when working with couples where violence has occurred. As mentioned, it is the presence of coercive control tactics that separate some of the more severe types of violence from those that are more situational (Johnson 2008). Therefore, careful questions regarding the role of the abuse need to be asked, as well as the use of standardized paper and pencil assessments for each partner. When issues of control or violence exist, separate interviews should occur to accurately assess for patterns of control or violence, as well as threats to safety that may otherwise be missed (e.g., Bograd and Mederos 1999). It is also important to emphasize that in cases where coercive control exists, couples therapy is contraindicated and may be dangerous. Also, it can be helpful to explore the role of control in the male's self-image, since for many violent men there is a strong element of need to control because of insecurity or shame-based fear (Holtzworth-Munroe and Meehan 2005). Some of these issues may have arisen because of shame or abuse of the perpetrator in the family of origin (Lisak 1995).

Identifying issues of control can be difficult because as Hines and Malley-Morrison (2005) point out, control patterns may be tied into the rationalization and gendered socializations that men may use. For example, men may defend their right to control as their "duty" or role as the man. Clinicians can be alert for these types of distortion and denial, which is a key clinical issue to be resolved if violence is to be treated successfully (Goldner 1999). Jenkins (2009) recommends that therapists judge men's explanations about abuse on the basis of three criteria: 1) Does the explanation help the perpetrator of the abuse take full responsibility for his abusive actions?; 2) Does the explanation 'point to' plausible and accessible solutions for ceasing the abuse?; and 3) Is the explanation sensitive to all levels of context, including the individual, and the gendered and socio-contextual in which the abuse occurs?

Lisak (1995) suggests that working with men who have issues with shame and distortions of masculinity should include a joint critique of issues including what it means to be male, vulnerable, or strong. For example, a clinician who is working with a violent man can approach his aggression with inquiries into his ability to connect with and empathize with his partner, as well as his own sense of powerlessness in situations where he feels threatened. This can be a challenging dance, as the treatment approaches that may be most helpful to these men may also be the most threatening. As Lisak says, "every time the therapist suggests, cajoles, or gently pushes the [man with trauma issues] to experience some emotional aspect of his experience, he or she is actually pushing the survivor into a confrontation with his gender internalizations" (p. 263). Therapists can carefully engage violent men in a mutual exploration about costs of gendered messages that may have been internalized into the man's life and relationship. For many of these men, this can be a turning point in their empathy with their partner (e.g., Jenkins 2009; Jory and Anderson 1999).

Therapists can assist in deconstruction of distortion, not by moralizing or shaming, but by inviting perpetrators to ethical accountability, and inviting victims to see their situations with more clarity and options (Jory and Anderson 1999). Goldner (1999) has suggested that: "Helping the man transcend his excuses and externalizations in order to acknowledge responsibility for violating and traumatizing his partner is an expression of a therapeutic commitment to him as well as to her" (p. 334). In other words, when we help men accept responsibility for their attitudes and actions we are more likely to help them reject future violence than if we accept distorted explanations that support violent attitudes.

Other issues of importance in relapse prevention include helping men stay with treatment. Gondolf and Jones (2001) found that men who completed a program were 44-64\% less likely to re-assault than non-completers. Clinicians should help men persist in treatment by focusing on the therapeutic relationship and by avoiding an adversarial approach in therapy. Also, several of our participants mentioned alcohol and substance use as triggers, and the presence of these makes relapse more likely. As many of half of all men in treatment for violence have alcoholic tendencies, and treatment addressing substance abuse should be a standard component of violence intervention programs. Research has shown that in a 
significant percentage of men who are violent, relapse is less likely after obtaining alcohol treatment alone (Stuart 2005). It has also been found that relative to non-users, substance abusers both perpetrate and receive the highest levels of intimate partner violence (Moore and Stuart 2004).

\section{Future Research}

The findings from this analysis suggest several areas for future exploration. For example, it would be helpful to know more about the role of remorse in treatment for perpetration, or in the overall cycle of violence (e.g., it may convince perpetrators or victims that it won't happen again). Also, as some of our participants talked about triggers and coping, it would be helpful to evaluate whether improved coping skills can reduce incidences of violence.

Additional studies could investigate the effects of addressing distortions in treatment. For example, do changes in the rationalization or denial of violence lead to changes in violent behavior? Are different types of perpetrators likely to use different types of distortion (e.g., do those who are situationally violent have different distortions than those who are in controlling relationships?). Although many participants accepted responsibility for their violence in our interviews, it was not evident that this was happening within the context of these relationships. It is important to know if there is a relationship between taking responsibility for perpetration and cessation of violence.

It also may be that a better understanding of how men explain their violent behavior may help to distinguish types of violent men. For example, quantitative research could explore whether there were significant differences between explanation types and the different types of batterers as delineated by either Johnson's (2008) or Holtzworth-Munroe and Stuart's (1994) typologies. Stover (2005) has suggested that this type of matching violent patterns with specific treatment approaches may be a key in relapse prevention. Also, further gendered issues could be explored. Although this paper focuses on heterosexual partnerships and violence, it is important to acknowledge the need for scholarship regarding these dynamics in gay and lesbian relationships with violence (McClennan 2005).

\section{Limitations \& Cautions}

Although small samples are common in qualitative research, it would be preferable to have more participants, particularly since this was a secondary analysis of data. Also, this was a clinical sample, which we wanted to use because it would add to the self-reflection abilities of the men. However, that likely was relevant in how these participants were able to acknowledge their role in the process and sometimes feel regret for it. Further research with more men and more diverse samples would help us know if these findings still are valid for perpetrators of many types.
Another area we would have liked to explore is what types of violence took place during these moments of IPV, whether it was primarily situational couple violence, intimate terrorism or a mixed version of these (Johnson 2008). The sample was gathered without digging into much of the history of the violence in the relationships, therefore we do not know details of length of violence, arrest histories, injuries or levels of control. It is likely that the various types of violence would relate to the types of distortions and reflections that are generated. As this was a qualitative sample with a diverse array of men and types of violence, it does not indicate specific directions for controlling or non-controlling violence. It would be helpful to follow up this work with larger and more distinct samples of men to see how their perceptions might vary based on differences in these histories.

Although it is helpful to explore the perceptions and explanations that men have in abusive relationships, it is always important to reiterate that we are not suggesting that these are reasons or causes of violence. Although we suggest there are triggers that may include relationship dynamics, we are trying to illustrate the complexity of violence rather than suggest it is systemic in the sense that there is equal power in relationships (Johnson 2006). It is becoming clearer from research that there are many interacting factors at work and many different versions of violent relationships. Therefore, although it always bears repeating that individuals are responsible for their behavior and that power differences exist, it is also evident we need to become more sophisticated in our understanding of the interactive nature of violence (Stith et al. 2005).

It is also important to note the socially constructed nature of this study. As an interactive process, research is by nature constructed, and the assumptions of those who designed the study, interviewed the participants, and analyzed and reported the results all play a part in its representation. Although this is typical of research, it bears reminding that while we hope this study is useful, we do not assume it is the last word on how perpetrators explain their violence. Nevertheless, it is our hope that these findings add further description to a perspective that is often underrepresented in discussions of the problem of intimate partner violence.

\section{References}

Babcock, J., \& Steiner, R. (1999). The relationship between treatment, incarceration, and recidivism of battering: a program evaluation of Seattle's Coordinated Community Response to Domestic Violence. Journal of Family Psychology, 13, 46-59.

Babcock, J. C., Green, C. E., \& Robie, C. (2004). Does batterers' treatment work? A meta-analytic review of domestic violence treatment. Clinical Psychology Review, 23, 1023-1053.

Barnett, O. W., Lee, C. Y., \& Thelen, R. E. (1997). Differences in forms, outcomes, and attributions of self-defense and control in interpartner aggression. Violence Against Women, 3, 462-481. 
Barriga, A. Q., Landau, J. R., Stinson, B. L., II, Liau, A. K., \& Gibbs, J. C. (2000). Cognitive distortion and problem behaviors in adolescents. Criminal Justice and Behavior, 27, 36-56.

Bograd, M., \& Mederos, F. (1999). Battering and couples therapy: universal screening and selection of treatment modality. Journal of Marital and Family Therapy, 25, 291-312.

Coker, A. L., Smith, P. H., Bethea, L., King, M. R., \& McKeown, R. E. (2000). Physical health consequences of physical and psychological intimate partner violence. Archives of Family Medicine, 9, 451-457.

Corbin, J., \& Strauss, A. (2008). Basics of Qualitative Research: Techniques and procedures for developing grounded theory (3rd ed.). Thousand Oaks: Sage.

Creswell, J. W. (2007). Qualitative inquiry and research design: Choosing among five approaches (2nd ed.). Thousand Oaks: Sage.

DeMaris, A., Benson, M. L., Fox, G. L., Hill, T., \& Van Wyk, J. (2003). Distal and proximal factors in domestic violence: a test of an integrated model. Journal of Marriage and Family, 65, 652-667.

Dobash, R. P., \& Dobash, R. E. (1981). Community response to violence against wives: Charivari, abstract justice, and patriarchy. Social Problems, 5, 563-581.

Eckhardt, C. I., \& Kassinove, H. (1998). Articulated cognitive distortions and cognitive deficiencies in maritally violent men. Journal of Cognitive Psychotherapy, 12, 231-250.

Eckhardt, C. I., \& Dye, M. L. (2000). The cognitive characteristics of martially violent men: theory and evidence. Cognitive Therapy and Research, 24, 139-158.

Eckhardt, C. I., Barbour, K. A., \& Davison, G. C. (1998). Articulated thoughts of maritally violent and nonviolent men during anger arousal. Journal of Counseling and Clinical Psychology, 66, 259269

Ehrensaft, M. K., \& Vivian, D. (1999). Is partner aggression related to appraisals of coercive control by a partner? Journal of Family Violence, 14, 251-266.

Eiskovits, Z., \& Enosh, G. (1997). Awareness of guilt and shame in intimate violence. Violence and Victims, 12, 307-322.

Felson, R. B., \& Messner, S. F. (2000). The control motive in intimate partner violence. Social Psychology Quarterly, 63, 86-94.

Felson, R. B., Ackerman, J. M., \& Gallagher, C. A. (2005). Police intervention and the repeat of domestic assault. Criminology, 45, 563-588.

Few, A., \& Rosen, K. (2005). Victims of chronic dating violence: how women's vulnerabilities link to their decision to stay. Family Relations, 54, 265-279.

Garcia-Monroe, C., Jansen, H., Ellsberg, M., Heise, L., \& Watts, C. H. (2006). Prevalence of intimate partner violence: findings from the WHO multi-country study on women's health and domestic violence. The Lancet, 368, 1260-1269.

Goldner, V. (1999). Morality and multiplicity: perspectives on the treatment of violence in intimate life. Journal of Marital \& Family Therapy, 25, 325-336.

Gondolf, E., \& Jones, A. (2001). Program effect of batterer programs in three cities. Violence \& Victims, 16, 693-704.

Grasmick, H. G., Hagan, J., Blackwell, B. S., \& Arneklev, B. J. (1996). Risk preferences and patriarchy: extending power-control theory. Social Forces, 75, 177-199.

Hattery, A. J. (2008). Intimate partner violence. New York: Routledge.

Heckert, D. A., \& Gondolf, E. W. (2000). Assessing assault self-reports by batterer program. Journal of Family Violence, 15, 181-197.

Heyman, R. E., \& Schlee, K. A. (1997). Toward a better estimate of the prevalence of partner abuse: adjusting rates based on the sensitivity of the Conflict Tactics Scale. Journal of Family Psychology, 11, $332-338$.

Hines, D. A., \& Malley-Morrison, K. (2005). Family violence in the United States: Defining, understanding, and combating abuse. Thousand Oaks: Sage.
Holtzworth-Munroe, A., \& Hutchinson, G. (1993). Attributing negative intent to wife behavior: the attributions of maritally violent versus nonviolent men. Journal of Abnormal Psychology, 102, 206-211.

Holtzworth-Munroe, A., \& Meehan, J. C. (2005). Partner violence and men: A focus on the male perpetrator. In W. M. Pinsof \& J. Lebow (Eds.), Family psychology: The art of the science (pp. 167-190). Oxford: Oxford University Press.

Holtzworth-Munroe, A., \& Stuart, G. L. (1994). Typologies of male batterers: three subtypes and the differences among them. Psychological Bulletin, 116(3), 476-497.

Holtzworth-Munroe, A., Rehman, U., \& Herron, K. (2000). General and spouse-specific anger and hostility in subtypes of maritally violent men and nonviolent men. Behavior Therapy, 31, 603-630.

Jaden, P. T., \& Thoennes, N. (2000). Prevalence and consequences of male-to-female and female-to-male intimate partner violence as measured by the national violence against women survey. Violence Against Women, 6, 142-161.

Jenkins, A. (2009). Becoming ethical: A parallel, political journey with men who have abused. Dorset: Russell House.

Jennings, J. L., \& Murphy, C. M. (2000). Male-male dimensions of malefemale battering: a new look at domestic violence. Psychology of Men and Masculinity., 1, 21-29.

Johnson, M. P. (2006). Conflict and control: gender symmetry and asymmetry in domestic violence. Violence Against Women, 12, $1003-1018$.

Johnson, M. (2008). A typology of domestic violence: Intimate terrorism, violent resistance, and situational couple violence. Boston: Northeastern University Press.

Johnson, M. P., \& Ferraro, K. J. (2000). Research on domestic violence in the 1990s: making distinctions. Journal of Marriage \& the Family, 62, 948-963.

Jory, B., \& Anderson, D. (1999). Intimate justice II: fostering mutuality, reciprocity, and accommodation in therapy for psychological abuse. Journal of Marital \& Family Therapy, 25, 349-364.

LaRossa, R. (2005). Grounded theory methods and qualitative family research. Journal of Marriage and Family, 67, 837-857.

Lisak, D. (1995). Integrating a critique of gender in the treatment of male survivors of childhood abuse. Psychotherapy, 32, 258-269.

McClennan, J. (2005). Domestic violence between same-gender partners: recent findings and future research. Journal of Interpersonal Violence, 20, 149-154.

Moffitt, T. E., Krueger, R. F., Caspi, A., \& Fagan, J. (2000). Partner abuse and general crime: how are they the same? How are they different? Criminology, 36, 199-232.

Moore, T., \& Stuart, G. (2004). Illicit substance use and intimate partner violence among men in batterers' intervention. Psychology of Addictive Behaviors, 18, 385-389.

National Coalition Against Domestic Violence. (2007). Domestic violence facts [Brochure]. Washington, DC: National Coalition Against Domestic Violence.

O'Leary, D. K., \& Williams, M. C. (2006). Agreement about acts of aggression in marriage. Journal of Family Psychology, 20(4), 656-662.

O’Neil, J. M., \& Harway, M. (1997). A multivariate model explaining men's violence toward women: predisposing and triggering hypotheses. Violence Against Women, 3, 182-203.

Porcerelli, J. H., Cogan, R., \& Hibbard, S. (2004). Personality characteristics of partner violent men: a Q-sort approach. Journal of Personality Disorders, 18, 151-162.

Ragg, D. M. (1999). Dimensions of self-concept as predictors of men who assault their female partners. Journal of Family Violence, 14, 315-329.

Richardson, D. R., Hammock, G. S., Smith, S. M., Gardner, W., \& Signo, M. (1994). Empathy as cognitive inhibitor of aggression. Aggressive Behavior, 20, 275-289.

Scott Tilley, D., \& Brackley, M. (2005). Men who batter intimate partners: a grounded theory of the development of male violence in intimate partner relationships. Issues in Mental Health Nursing, 26, 281-298. 
Seale, C. (2004). Using data archives for secondary analysis. In C. Seale (Ed.), Researching society and culture (pp. 356-365). Thousand Oaks: Sage.

Shepard, M. F., Falk, D. R., \& Elliott, B. A. (2002). Enhancing coordinated community responses to reduce recidivism in cases of domestic violence. Journal of Interpersonal Violence, 17, 551-569.

Stith, S. M., McCollum, E. E., Rosen, K. H., Locke, L., \& Goldberg, P. (2005). Domestic violence focused couples treatment. In J. Lebow (Ed.), Handbook of clinical family therapy (pp. 406-430). New York: John Wiley \& Sons.

Stover, C. (2005). Domestic violence research. Journal of Interpersonal Violence, 20, 448-454.
Strauss, A., \& Corbin, J. (1998). Basics of Qualitative Research: Techniques and procedures for developing grounded theory (2nd ed.). Thousand Oaks: Sage.

Stuart, G. (2005). Improving violence intervention outcomes by integrating alcohol treatment. Journal of Interpersonal Violence, 20, 388-393.

Whiting, J. B., Oka, M., \& Fife, S. T. (2012). Appraisal distortion and intimate partner violence: gender, power and interactions. Journal of Marital and Family Therapy. doi:10.1111/j.1752-0606. 2011.00285.x.

Wilkinson, D. L., \& Hamerschlag, S. J. (2004). Situational determinants in intimate partner violence. Aggression and Violent Behavior, 10, 333-361. 